\title{
Instructor Perspectives of Online VERSUS FACE-TO-FACE EdUCATION AT A JESUit InSTITUTION: INSTRUCTOR FACTORS
}

\author{
Lynn A. Fish and Coral R. Snodgrass
}

Lynn A. Fish and Coral R. Snodgrass both hold the rank of Professor of Management, Canisius College, 2001 Main Street, Buffalo, NY 14208

\begin{abstract}
While instructors are a critical component of the education paradigm, research into instructor perspectives on online education is sparse. The purpose of this study is to explore factors in instructor perceptions of online versus face-to-face education at a Jesuit, Catholic private University in the northeast. A literature review indicates that demographic, individual instructor and program differences are the salient factors that influence these perceptions. This paper addresses the individual instructor factors of motivation, discipline, self-directed, independence, schedule flexibility, time and cost investment, appropriateness of online education, preference for online or face-to-face, and happiness.
\end{abstract}

Keywords: instructor perceptions, online education, individual 
DOI: http://dx.doi.org/10.15239/j.brcacadje.2018.07.01.ja02

\section{LITERATURE REVIEW}

The purpose of this study is to explore differences in instructor perceptions of online verses face-to-face (FTF) instruction. The impact of online education will continue to grow in higher education; however, as the literature review highlights there are few studies that address instructor perspectives (rather than student perspectives). Recent research highlighted the increase in online education throughout the higher education system (Allen \& Seamen, 2013). In addition, the issues are ever changing. A recent study on instructor attitudes with respect to instructor online presence noted that studies into instructor and student perceptions continue to evolve as technology evolves (Richardson et al., 2016). In studies of student perceptions of online versus FTF education, gender, age, experience, and academic background, each of these factors yield differing results over time (Billings, Skiba \& Connors, 2005; Dobbs et al. 2009; Tanner et al., 2004a, 2004b; Fish \& Snodgrass, 2014). There is a need to assess both the student and instructor's perspectives with respect to online education (Shieh, Gummer \& Niess, 2008). Information and knowledge regarding instructor beliefs are important to improving instructional effectiveness (Farrell \& Kun, 2008). The question for this study is: How do instructors - those that have taught and those that have not taught online - perceive online education compared to face-to-face (FTF) education today? Our research aims to provide a timely answer to this question.

While other researchers addressed aspects of this question in the past, results are mixed, sparse and change over time. In 2004, faculty perceptions (at public and nonprofit private institutions in the United States) on the effectiveness of online instruction in terms of the seven principles of effective undergraduate education revealed that faculty rated online education slightly more effective overall and more effective for promoting 
prompt feedback, time on task, respect for diverse learning styles and communicating high expectations (Guidera, 2004). However, instructors rated online education as less effective on promoting student-to-instructor contact and cooperation among students (Guidera, 2004). Contrastingly, in another more recent study, instructors without online experience felt that online teaching would never be as effective as traditional classroom teaching (Fish \& Gill, 2009). The study reported instructor perceptions on teaching and learning outcomes as strongly influenced by experience teaching online as an instructor. Those with positive experiences felt that online and FTF instruction yielded equivalent outcomes, while those instructors with no online or negative experiences indicated that outcomes were not the same. (Fish \& Gill, 2009). Over a decade ago, many instructors perceived online instruction as inferior to traditional teaching (Wilson, 2001), and instructors gravitated towards instructional practices that were most comfortable to them (Hinson \& LaPrairie, 2005). Over a decade ago, using the Delphi method, 36 business instructors from AACSB-accredited universities who taught online completed a survey on best practices in online education (Gallegos \& Butters, 2007). Results from the study highlighted the need for incentives to professors to teach online and the need for professors to learn pedagogy respective to the online environment (Gallegos \& Butters, 2007). Similarly, in a 2009 survey of over 10,000 faculty members from close to 70 colleges and universities, most instructors felt that their institutions did not provide online support and incentives to teach online (Seaman, 2009). However, these surveys were conducted over 8 years ago as MOOCs and online education were just starting to explode.

A literature review reveals a number of factors that may impact upon instructors' perceptions of online education. These factors fall into three broad categories: demographic, individual and program. There are demographic factors such as age, gender, major or discipline, level taught, faculty rank, and self-reported technological skill level. There are also individual (personal) factors that are specific to the instructor, such as motivation, discipline, self-directed learning and independence, 
schedule flexibility, time and cost investment, preference, happiness and appropriateness for learning environment, as well as cultural differences. The third category includes program factors, which are decisions that the instructor makes in developing the course, such as course organization, academic difficulty, program quality, academic integrity, instructor-toinstructor involvement and collegiality, student-to-instructor interaction, communication mechanisms, student-to-student interaction, schedule flexibility, and program technologies. Since the intent of this paper is to address the individual instructor factors, we summarize the literature for these factors briefly below.

\section{Individual (Personal) Factors.}

Separate from these broader demographic factors, a set of individual or personal factors exist in the literature. A literature search for instructor perceptions of online education related to motivation, discipline, selfdirected learning, independence, schedule flexibility, time and cost investment, preference, happiness, and an instructor's perception of the appropriateness of online yielded few studies. Typical barriers to online teaching include faculty time, rewards, workload, lack of administrative support, cost, course quality and technology issues (Chang et al., 2014). With respect to motivation, one older study cited that training can address the importance of faculty committing themselves and therefore, the motivation, to online teaching (Fennema, 2003). Instructors from a public university in the southeast who did not teach online felt that online courses were difficult to organize and teach (Fish \& Gill, 2009). Online teaching provides faculty with flexibility in time and location. While instructor cost investment perceptions have not been studied, with respect to time investment, online instructors must be prepared to address the time demands in designing and delivering a student-centered online course (Kohtanek \& Hein, 2000). U.S. and South Korean educators indicated that time management and technical support accessibility posed serious challenges to online interaction and education (Yoo et al., 2014). 
As for the appropriateness of online education, a recent study revealed that some online instructors still question the fit between their educational philosophies and online teaching (Terosky \& Heasley, 2015). In an attempt to address this gap, administrators often point to instructor online orientation and development programs. Research into online faculty development programs cite the need to include the faculty member's needs in content and format recommendations as well as the need for 'followup' education and structures that build trust and connections amongst online faculty (Terosky \& Heasley, 2015). Another study highlights the critical importance of the institution's commitment and support to online training prior to the instructor teaching online (Shieh et al., 2008). Early studies reported that not all instructors teaching styles are suited to online teaching (Christianson, Tiene \& Luft, 2002). Another study highlighted the importance of sufficient training and support for faculty to enhance their ability to deliver online instruction (Bennett \& Lockyer, 2004). While instructors' perceptions did not differ significantly between those instructors with or without training support, online instructors who receive enough training support performed better on instructional design, learning assessment, and technology use than online instructors who received little or no training support (Chang et al., 2014). As a faculty member transitions from the traditional FTF to the online environment, faculty perceptions reflect the need for comprehensive training (Chang et al., 2014). The ability to work anytime and from any Internet accessible computer were cited by instructors as factors that influenced their preference to take online professional development courses instead of FTF (Thomas, 2010).

While the factors cited above have not been significantly researched, some research into instructor cultural differences has been performed. Online, distance learning has not eliminated cultural differences (StarrGlass, 2011), and these differences are demonstrated through communication styles and difficulty in understanding language (Wang, 2007). As instructors design courses, instructors address online-learning interaction between themselves and the student and student-to-student inter- 
action. However, depending upon the culture, student characteristics, faculty characteristics and institutional parameters, this may be designed differently (Yoo et al., 2014). For example, Korean educators under the Confucian culture are more likely to emphasize their role as the content provider instead of a learner helper as in the U.S. (Yoo et al., 2014). U.S. instructors consider interaction as a necessary component into successful online learning and teaching (Yoo et al., 2014). Instructor perceptions on interaction differ; however, in a study of Korean and US instructors, both groups perceived that interaction was an essential component to online education as it allows student engagement in the learning environment (Yoo et al., 2014). Interestingly, Korean instructors felt that online interaction completely replicated FTF interaction (Yoo et al., 2014).

\section{Summary}

While not intended to be a comprehensive review of literature on instructor perceptions of online education, the literature review serves to outline the lack of research in this area. As noted above, most available research is over a decade old, when available technology and instructor understanding of online education was very different. Also, the few studies performed differ in size (small, medium, large universities), audience (e.g. scientific versus social sciences, business versus nonbusiness, and graduate versus undergraduate), and method of research (e.g. interview, survey). The context of the study may be an important factor to consider in interpretation of the survey results. As we noted in a similar study with respect to student perceptions (Fish \& Snodgrass, 2016a, 2016b), as technology changes, online education changes and perceptions change as well. As noted above, there are very few studies on instructor's perceptions and the demographic, individual and program factors, and many that exist are over 10 years old.

We conducted our study at a mid-sized, Jesuit, Catholic, private school in the United States with a focus on teaching. The research focus lies in uncovering instructor perceptions that offers instruction in traditional arts and sciences, education and business and where FTF class sizes 
average 17 students. While online education is a growing educational method (Allen \& Seaman, 2013), not all faculty trained in or participated in online course development. Based upon the literature, the intent of this research is to explore instructors' perceptions of the online experience for those who have taught in and those who have never taught in the online environment. Specifically, this paper seeks to explore individual instructor perceptions: What are the individual instructor factors that differ between groups? Why do instructors at a teaching university choose online or traditional FTF classes? Which medium do instructors at a teaching university prefer? Specific individual instructors perceptions addressed in this research include motivation, discipline, self-directed learning and independence, schedule flexibility, time and cost investment, preference, happiness and appropriateness for learning environment. Theoretically, instructors should perceive the environments equally and not favor either traditional or online education.

\section{PREVIEW COMPLETE}

This completes the limited preview of this paper. Please visit the link below to purchase.

\section{Citation Information}

Fish, Lynn A., and Coral R. Snograss. "Instructor Perspectives of Online versus Face-to-Face Education at a Jesuit Institution: Instructor Factors ." The BRC Academy fournal of Education 7, no. 1 (2018): 37-53. http:// dx.doi.org/10.15239/j.brcacadje.2018.07.01.ja02 